\title{
ANALYSIS OF HEMOGLOBIN LEVELS AND LEUKOCYTE COUNT IN NEONATES WITH HYPERBILIRUBINEMIA
}

\author{
Dewi Suharti, Sulina Yanti Wibawa, Muthmainnah
}

Department of Clinical Pathology, Faculty of Medicine, Hasanuddin University/Dr. Wahidin Sudirohusodo Hospital Makassar, Indonesia. E-mail:dedew.ds@gmail.com

\begin{abstract}
Hyperbilirubinemia is one of the most common clinical phenomena in the neonatal patient. The etiology is generally physiological, only about $10 \%$ being pathological. It is essential for clinicians to distinguish between physiological and pathological hyperbilirubinemia, because uncontrolled pathological conditions can cause severe complications of kern icterus, one of the causes of death in infants. This study was aimed to know the level of hemoglobin and leukocyte count in neonates with hyperbilirubinemia in the Dr. Wahidin Sudirohusodo Hospital, Makassar. This study was a retrospective by obtaining data of all neonatal patients with a diagnosis of hyperbilirubinemia, who underwent hemoglobin and leukocyte count test. The data were classified into two groups: physiological and pathological hyperbilirubinemia. Statistical tests were performed to assess the association of hemoglobin levels and leukocytes count between the two groups. A total of 144 data were collected, 54 physiological and 90 pathological hyperbilirubinemia. In physiological hyperbilirubinemia, hemoglobin levels and leukocyte counts were found to be normal, whereas in pathological hyperbilirubinemia, anemia and leukocytosis developed and the difference between the two groups was statistically significant $(p<0.001)$. Anemia was found in neonates with pathological hyperbilirubinemia caused by Respitarory Distress of Newborn (RDN), Low Birth Weight (LBW), sepsis, hemolytic, and hemorrhagic. Leukocytosis was found in pathological hyperbilirubinemia caused by sepsis. There was a significant difference between the incidence of anemia and leukocytosis in physiological and pathological hyperbilirubinemia. It can be concluded that routine blood tests can be used to distinguish whether hyperbilirubinemia experienced by a neonatal patient is a physiological or pathological condition, so that it can be one of the tests suggested when the neonate has hyperbilirubinemia.
\end{abstract}

Key words: Physiological hyperbilirubinemia, pathological hyperbilirubinemia, neonates, anemia, leukocytosis

\section{INTRODUCTION}

Hyperbilirubinemia is one of the most common clinical phenomena in neonates. The incidence of hyperbilirubinemia is quite high and increasing. Data in the United States showed that, from 4 million newborns each year, about $65 \%$ have hyperbilirubinemia. Existing epidemiological data suggest that over $50 \%$ of newborns develop clinically detectable hyperbilirubinemia within the first week of birth. ${ }^{1-3}$ Hyperbilirubinemia in neonates is a condition with increased bilirubin and is characterized by icterus or jaundice. Jaundice in neonates will be visible when the total bilirubin level is $>5 \mathrm{mg} / \mathrm{dL}$ ( $>85 \mu \mathrm{mol} / \mathrm{L}$ ). Icterus or jaundice occurs due to the accumulation of bilirubin in the blood so that the skin and sclera appearyellowish. ${ }^{1-6}$

Most of the hyperbilirubinemia in neonates is normal (physiological), only about $10 \%$ is pathological. Etiology of pathological hyperbilirubinemia include hemolytic disease, prematurity, Low Birth Weight
(LBW), asphyxia, respiratory disease, hemorrhagic, and systemic infection (neonatal sepsis). It is crucial for the clinician to distinguish between them because uncontrolled pathological hyperbilirubinemia and poor management can lead to kernicterus, a severe complication leading to death in infants. ${ }^{1.5}$

Separating physiological from pathological hyperbilirubinemia can be done by considering the gestational age, clinical symptoms, and bilirubin level. The characteristics of physiologic hyperbilirubinemia are occurring on day $2-3$, total bilirubin level $<12 \mathrm{mg} / \mathrm{dL}$ in full-term neonates and $<10 \mathrm{mg} / \mathrm{dL}$ in preterm neonates, rate of bilirubin level elevation $<5 \mathrm{mg} / \mathrm{dL} /$ day, direct bilirubin level $<1 \mathrm{mg} / \mathrm{dL}$, cessation of jaundice in the first ten days of life, and no proven related pathological condition. Pathologic hyperbilirubinemia characteristics include jaundice occurring in the first twenty-four hours of life, total bilirubin $>12 \mathrm{mg} / \mathrm{dL}$ in full-term and $>10 \mathrm{mg} / \mathrm{dL}$ in preterm neonates, rate of bilirubin elevation $>5 \mathrm{mg} / \mathrm{dL} /$ day, direct bilirubin level 
$>1 \mathrm{mg} / \mathrm{dL}$, persistent jaundice after the first two weeks, and known related pathologic conditions, such as hemolytic disease, infections or other pathologic conditions. ${ }^{1,3-7}$

Mishra et al. stated that there were differences in hemoglobin levels and leukocyte count in physiological and pathological hyperbilirubinemia. Neonates with physiological hyperbilirubinemia were reported to have normal hemoglobin and leukocyte count, while neonates with pathological hyperbilirubinemia had anemia, reticulocytosis, and leukocytosis. Shah et al. also mentioned that anemia was commonly found in neonates with pathological hyperbilirubinemia. ${ }^{6,7}$

The lifespan of erythrocytes in neonates is shorter (70-90 days) than adults (120 days). It leads to the increase of bilirubin levels in neonates (physiological). The physiological hyperbilirubinemia does not affect hemoglobin levels and leukocyte count in neonates. The mechanisms of anemia and leukocytosis in pathological hyperbilirubinemia are associated with its etiology. ${ }^{1,25-8}$

Study on hemoglobin levels and leukocyte count in neonates with hyperbilirubinemia, to our knowledge, has never been done in Indonesia, especially in Makassar. Based on the background, the researchers wanted to know the level of hemoglobin and leukocyte count in neonates with hyperbilirubinemia in the Dr. Wahidin Sudirohusodo Hospital, Makassar.

\section{METHODS}

This study was a retrospective study, with the study population being data of all neonates with a clinical diagnosis of hyperbilirubinemia treated in the children's department of the Dr. Wahidin Sudirohusodo Hospital Makassar. Sample collection was done by taking data from the medical record of neonates with a clinical diagnosis of hyperbilirubinemia from January 2016 - December 2016 in the Dr. Wahidin Sudirohusodo Hospital.

The study samples were all sample population tested for hemoglobin levels and leukocyte counts. Samples were classified into two groups: physiological and pathological hyperbilirubinemia. Hemoglobin levels and leukocyte counts were obtained from routine blood tests tested using an automatic hematology analyzer (Sysmex XN 1000, Japan). From the data of hemoglobin level and leukocyte count obtained, the samples were classified as anemia and leukocytosis based on hemoglobin and leukocytecount reference value used in the Clinical Pathology Laboratory of Dr. Wahidin Sudirohusodo
Hospital Makassar. Ethical clearance was obtained from the Medical Research Ethics Commission, Faculty of Medicine, Hasanuddin University/Dr. Wahidin Sudirohusodo Hospital-Hasanuddin University Hospital, Makassar. The association of anemia with hyperbilirubinemia was analyzed using the Chi-Square test, while the association of leukocytosis with hyperbilirubinemia used Fisher Exact test. Statistical test results were considered significant if the p was $<0.05$.

\section{RESULTS AND DISCUSSION}

Data from 144 neonates with hyperbilirubinemia was obtained, with characteristics as shown in Table 1. Sex distribution in this study was consistent with the results of Shah et al. and Ramadevi et al., who reported that hyperbilirubinemia was more common in males (> 50\%) compared to females $(<40 \%)$. Mishra et al. reported a different result stating that the prevalence of hyperbilirubinemia was equal in males and females. As far as knowledge, there was no literature and research mentioning the influence of sex on hyperbilirubinemia. ${ }^{6,7,9}$

Table 1. Sample characteristics

\begin{tabular}{lcc}
\hline Variable & $\mathbf{n = 1 4 4}$ & $\begin{array}{c}\text { Percentage } \\
\text { (\%) }\end{array}$ \\
\hline Sex & & \\
Male & 85 & 59 \\
Female & 59 & 41 \\
Age (day) & & \\
$0-1$ & 99 & 69.5 \\
$2-4$ & 28 & 19.5 \\
$5-7$ & 8 & 5.5 \\
$8-14$ & 8 & 5.5 \\
$15-30$ & 1 & 0.6 \\
Gestational age & & \\
Full-term & 65 & 45.1 \\
Preterm & 79 & 54.9 \\
Hyperbilirubinemia & & \\
Physiological Hyperbilirubinemia & 54 & 37.5 \\
Pathological Hyperbilirubinemia & 90 & 62.5 \\
RDN & 36 & 25 \\
$\quad$ LBW & 27 & 18.7 \\
Sepsis & 25 & 17.4 \\
Hemolytic & 1 & 0.7 \\
Neonatal hemorrhagic & 1 & 0.7 \\
\hline
\end{tabular}

RDN = Respiratory Distress of Newborn, LBW = Low Birth Weight

This study showed that hyperbilirubinemia was more prevalent in the group of patients aged 0-1 day, which was 99 subjects (69.5\%). Shah et al. mentioned that the mean age of neonates with hyperbilirubinemia was $2.97 \pm 1.2$ days. 
Physiological hyperbilirubinemia usually occurs after 24 hours ( 1 day), total bilirubin (Bil T) peaks on the $3^{\text {rd }}$ day until the $5^{\text {th }}$ day and decreases after the $7^{\text {th }}$ day. Hyperbilirubinemia developed within the first 24 hours ( 0 days) is suspected as pathological hyperbilirubinemia, with high bilirubin levels persisting until day 8 in full-term neonates and $\geq 14$ days in preterm neonates. ${ }^{1,2,5,7}$

Table 1 showed that hyperbilirubinemia was more common in preterm $(54.9 \%)$ than full-term neonates (45.1\%). A previousstudy by Payal et al. and Kumar et al. showed a similar result. The risk of hyperbilirubinemia in preterm infants is higher due to an impaired liver function which causes inhibition in bilirubin excretion and results in bilirubin accumulation in the circulation and bilirubin deposition in the tissue. ${ }^{1-5,8,10-11}$ Table 1 also showed the incidence of physiological hyperbilirubinemia of $37.5 \%$. The most common pathological hyperbilirubinemia etiology was RDN in 36 subjects (25\%) followed by LBW in 27 subjects (18.7\%) and sepsis in 25 subjects (17.4\%). Short erythrocyte lifespan causes a high rate of erythrocyte destruction (hemolysis) resulting in increased bilirubin production. This mechanism causes physiological hyperbilirubinemia in the neonates. This mechanism also occurs in pathological hyperbilirubinemia due to hemolytic and hemorrhagic causes which results in increased bilirubin production. ${ }^{1-5,8}$

A study by Syamsir et al. stated that elevated bilirubin levels might be due to sepsis. Various studies had concluded that sepsis might cause liver dysfunction, leading to inhibition of bilirubin excretion. ${ }^{12}$ The mechanism of hyperbilirubinemia in
LBW is caused by impaired liver function, causing inhibition in bilirubin excretion which results inbilirubin accumulation in the circulation and bilirubin deposition in the tissue. In RDN, hyperbilirubinemia occurs due to disruption of protein and bilirubin bonds as a result of hypoxia or acidosis. $^{1-3,5}$

From a total of 144 data, the mean of hemoglobin level in physiological hyperbilirubinemia was $17.94 \mathrm{~g} / \mathrm{dL} \pm 1.32 \mathrm{~g} / \mathrm{dL}$. The mean value of hemoglobin level in pathological hyperbilirubinemia was $13.75 \mathrm{~g} / \mathrm{dL} \pm 1.94 \mathrm{~g} / \mathrm{dL}$. The mean value of leukocyte count in physiological hyperbilirubinemia was $11.92 \mathrm{~g} / \mathrm{dL} \pm 2.67 \mathrm{~g} / \mathrm{dL}$, whereas in pathological hyperbilirubinemia the mean value was $17.79 \mathrm{~g} / \mathrm{dL}$ $\pm 9.09 \mathrm{~g} / \mathrm{dL}$ (Table 2 ).

Classifying the samples as anemia and normal was based on data of hemoglobin levels, using the neonatal hemoglobin reference value. Further analysis of the incidence of anemia was performed in the two groups, and anemia was found in 84 subjects (out of 90 subjects) with pathological hyperbilirubinemia, while in physiological hyperbilirubinemia, only two subjects had anemia out of the total of 54 subjects. Chi-Square test showed that there was a significant difference between the incidence of anemia in physiological and pathological hyperbilirubinemia with a p-value $<0.001$ (Table 3 ).

Shah et al. and Misrah et al., obtained similar results, although the pathological hyperbilirubinemia etiology was slightly different from our results. Physiological hyperbilirubinemia did not affect hemoglobin levels in neonates, so that hemoglobin levels were found within normal limits. This study

Table 2. Hemoglobin level and leukocyte count in hyperbilirubinemia

\begin{tabular}{lcccc}
\hline Hyperbilirubinemia & N & Minimum & Maximum & Mean \pm SD \\
\hline Hemoglobin level $(\mathrm{g} / \mathrm{dL})$ & & & & \\
Physiological & 54 & 16 & 21.4 & $17.94 \pm 1.32$ \\
Pathological & 90 & 6.3 & 20.2 & $13.75 \pm 1.94$ \\
Leucocyte count $\left(\times 10^{3} / \mu \mathrm{L}\right)$ & & & & \\
Physiological & 54 & 7.8 & 18.9 & $11.92 \pm 2.67$ \\
Pathological & 90 & 5.1 & 44.1 & $17.79 \pm 9.09$ \\
\hline
\end{tabular}

Table 3. Correlation of anemia and hyperbilirubinemia

\begin{tabular}{|c|c|c|c|c|}
\hline & \multicolumn{2}{|c|}{ Hyperbilirubinemia } & \multirow{2}{*}{$\mathbf{N}$} & \multirow{2}{*}{$\mathbf{p}^{*}$} \\
\hline & Physiological & pathological & & \\
\hline \multicolumn{5}{|c|}{ Anemia } \\
\hline Yes & 2 & 84 & 86 & \multirow{3}{*}{$<0.001$} \\
\hline No & 52 & 6 & 58 & \\
\hline Total & 54 & 90 & 144 & \\
\hline
\end{tabular}

${ }^{*}$ Chi-Square test 
Table 4. Correlation of leukocyte count and hyperbilirubinemia

\begin{tabular}{|c|c|c|c|c|}
\hline & \multicolumn{2}{|c|}{ Hyperbilirubinemia } & \multirow{2}{*}{$\mathbf{N}$} & \multirow{2}{*}{$\mathbf{p}^{*}$} \\
\hline & Physiological & pathological & & \\
\hline \multicolumn{5}{|c|}{ Leukocytosis } \\
\hline Yes & 0 & 23 & 23 & \multirow{3}{*}{$<0.001$} \\
\hline No & 54 & 67 & 121 & \\
\hline Total & 54 & 90 & 144 & \\
\hline
\end{tabular}

*Fishers Exact test

showed that anemia occurred in pathological hyperbilirubinemia caused by RDN, sepsis, hemolytic and hemorrhagic., ${ }^{1,26-7}$

The causes of anemia in the neonates can be classified into three mechanisms; blood loss increased erythrocyte destruction and decreased erythrocyte production. Anemia in pathological hyperbilirubinemia due to hemolysis and sepsis is caused by increased erythrocyte destruction, while anemia in hyperbilirubinemia due to RDN occurs as a result of decreased erythrocyte production. Blood loss is the cause of anemia in hyperbilirubinemia due to hemorrhagic disease. ${ }^{1,5-8,13}$

Based on the data of leukocyte count, the sample was divided into two groups; leukocytosis and normal. The incidence of leukocytosis in physiological and pathological hyperbilirubinemia was analyzed statistically. The results showed no leukocytosis was found in physiological hyperbilirubinemia, while in pathological hyperbilirubinemia was found 23 out of 90 subjects had leukocytosis. Fisher Exact test was performed to assess the association of leukocytosis with hyperbilirubinemia and found significant differences between leukocytosis incidence in physiological and pathological hyperbilirubinemia with a $p$-value $<0.001$ (Table 4).

The results of this study were consistent with the Mishra et al. who mentioned that leukocytosis occurred in pathological hyperbilirubinemia due to sepsis. Leukocytosis in neonatal sepsis results from the interaction of complex responses between pathogenic microorganisms and hyperinflammatory states. ${ }^{6}$

\section{CONCLUSION AND SUGGESTION}

There was a significant difference between the incidence of anemia and leukocytosis in physiological and pathological hyperbilirubinemia ( $p<0.001)$. Neonates with pathological hyperbilirubinemia due to RDN, LBW, sepsis, hemolytic, and hemorrhagic had anemia, whereas neonates with physiological hyperbilirubinemia had normal hemoglobin levels. Leukocyte count in pathological hyperbilirubinemia was found to be elevated, but not in physiological hyperbilirubinemia. In this study, leukocytosis was found in pathological hyperbilirubinemia due to sepsis.

From the results of this study, it can be concluded that routine blood tests can be used to distinguish whether hyperbilirubinemia in neonates is a physiological or pathological condition. This test can be one of the tests suggested evaluating neonates with hyperbilirubinemia, so that diagnosis and therapy can be more targeted and severe complications can be prevented.

\section{REFERENCES}

1. Namasivayam A, Waldemar AC. Jaundice and hyperbilirubinemia in the newborn. Nelson text book of pediatrics. $19^{\text {th }}$ Ed., Philadelphia USA, WB. Saunders Company, 2011; 603 - 8.

2. Rinawati Rohsiswatmo. Indikasi terapi sinar pada bayi menyusui yang kuning. [cited at April 7, 2017]. Available at: http://www.idai.or.id/artikel/klinik/asi/ indikasi-terapi-sinar-pada-bayi-menyusui-yangkuning.

3. Tjipta GD, Azlin E, Sianturi P, Lubis BM. Hiperbilirubinemia pada neonatus. [cited at April 7, 2017]. Available at: http://ocw.usu.ac.id.

4. Barrington KJ, Sankaran K. Guideline for detection management and prevention of hyperbilirubinemia in term and late preterm newborn infants. Canada, Canadian Pediatric Society Fetus and Newborn Committee. 2007; 1-5.

5. American Academy of Pediatrics. Subcommittee on hyperbilirubinemia. Management of hyperbilirubinemia in the newborn 35 or more weeks of gestation. Journal of the American Academy of Pediatrics, 2004; 104(1): 297-316. [cited on May 5, 2017]. Available at: http://pediatrics.aappublications. org/content/114/297.

6. Mishra JP, Mishra J, Padhi RK, Mishra S, Manjareeka M. Hematological profile in neonatal jaundice. Journal of Basic Clinical Physiology and Pharmacology, 2013; 0087. [cited on May 5, 2017]. Available at: https://www.ncbi.nlm.nih.gov/pubmed/24114906.

7. Shah A, Shah K, Shah V. Study of hematological parameters among neonates admitted with neonatal jaundice. Journal of Evolution of Medical and Dental Sciences, 2012; 1(2): 203-208. [cited on May 5, 2017]. 
Available at:https://www.jemds.com/ data_pdf/ 2_AmarShah.pdf.

8. Dessypris EN, Sawyer ST. Erythropoeisis and destruction of erythrocyte. Wintrobe's clinical hematology. $12^{\text {th }}$ Ed., Philadelphia USA, Lippincott Williams and Wilkins, 2009; 442-500.

9. Ramadevi GV, Bhuvaneswari M, Sam Prasad G, Sireesha S. Clinical profile and outcome of term and preterm newborns with hyperbilirubinemia admitted in SNCU of a teaching hospital. [cited on August 17, 2017]. Available at: https://jemds.com/data_pdf/ 2_Kumarvel--Divya--Man.pdf.

10. Kumar A, Srivastava S. Prevalence of hyperbilirubinemia and causative factors among neonates: A clinical study. Journal of Advanced Medical and Dental Sciences Research, 2016. [cited on
August 17, 2017]. Available at: http://www. jamdsr.com.

11. Mittal P, Tank P, Agarwal Y, Tank R, Singh A, Goyal V. Neonatal hyperbilirubinemia: An experience of 212 cases from a tertiary care setup. Saudi Journal of Medical and Pharmaceutical Sciences. [cited on August 17, 2017]. Available at:http://scholarsmepub. com/sjmps/.

12. Syamsir B, Muhiddin R, Bahrun U. Analisis parameter laboratorium sebagai penanda sepsis pada neonatus dengan hiperbilirubinemia. Makassar, Program Studi Ilmu Patologi Klinik Fakultas Kedokteran Universitas Hasanuddin, 2016; 1-12.

13. Kirsten E, Crowley MD. Neonatal anemia. [cited on August 17, 2017]. Available at: https://www. ucsfbenioffchildrens.org/pdf. 